\title{
One-step preparation of enantiopure L- or D-amino acid benzyl esters avoiding the use of banned solvents
}

Dipartimento di Scienze Farmaceutiche, Sezione "Pietro Pratesi”, Università degli Studi di Milano, via Mangiagalli 25, I-20133, Milano, Italia

marco.pallavicini@unimi.it, phone: +3902 50319336. Fax: +390250319359.

\begin{abstract}
The enantiomers of amino acid benzyl esters are very important synthetic intermediates. Many of them are currently prepared by treatment with benzyl alcohol and $p$-toluenesulfonic acid in refluxing benzene or carbon tetrachloride, to azeotropically remove water, and then precipitated as tosylate salt by adding diethyl ether. Here, we report a very efficient preparation of eight L- or D-amino acid benzyl esters (Ala, Phe, Tyr, Phg, Val, Leu, Lys, Ser), in which these highly hazardous solvents are dismissed by using cyclohexane as a water azeotroping solvent and ethyl acetate to precipitate the tosylate salt. With some work-up modifications and lower yield, the procedure can be applied also to methionine. Chiral HPLC analysis shows that all the benzyl esters, including the highly racemizable ones such as those of phenylglycine, tyrosine and methionine, are formed enantiomerically pure under these new reaction conditions thus validating the solvents replacement. Contrariwise, toluene cannot be used in place of benzene or carbon tetrachloride because leading to partially or totally racemized amino acid benzyl esters depending on the polar effect of the amino acid $\alpha$-side chain as expressed by Taft's substituent constant $\left(\sigma^{*}\right)$.
\end{abstract}

\section{Keywords}

amino acid benzyl ester $\cdot$ water azeotrope $\cdot$ racemization $\cdot$ chiral HPLC $\cdot$ cyclohexane $\cdot$ toluene . Taft's substituent constant 


\section{Introduction}

The enantiomers of $\alpha$-amino acid benzyl esters are very important synthetic intermediates. Apart from their obvious wide use, documented by a great number of papers, in peptides synthesis as C-protected amino acids derivatives, easily deprotectable after peptide bond formation, they are often employed to construct also more complex chiral molecules of non-peptide nature. In fact, unlike the carbohydrates derivatives, the $\alpha$-amino acid esters and, in particular, the benzyl esters are available in both the enantiomeric forms from the 'chiral pool'. Furthermore, they do not suffer from that unneeded profusion of chirality, carbon atoms and reactive functions, which is typical of carbohydrates and which makes necessary multiple protecting groups and costly transformations to smaller, more useful species. Recent examples can be cited to exemplify the use of $\alpha$-amino acid as benzyl esters for the synthesis of non-peptide molecules in unichiral form: azetidinone-isothiazolidinones from L-alanine and L-phenylglycine (Cerić 2010), 4-methylcarboxy-1,4-benzodiazepine2,5-diones from L-alanine and L-leucine (Verdié 2008), $\alpha$-methylene- $\beta$-hydroxy- $\gamma$-carboxy- $\gamma$-lactams from Lphenylalanine, L-valine, L-leucine and L-threonine (Tekkam 2013), isochaetominines from D- or L-valine, alanine and tryptophan (Mao 2016), differently substituted piperazine-2,5-diones (Liu, Wu et al. 2007) and imidazoacetates (Liu, Zhao et al. 2010).

Our interest in $\alpha$-amino acid esters has built on their use as unichiral synthons (Bolchi, Pallavicini et al. 2007; Bolchi, Valoti, Gotti et al. 2015) and on their potentially useful $\alpha, \beta$-dehydrogenation (Pallavicini 2010) and then it has focused on some important issues in the preparation and analytical characterization of the dibenzyl esters of L-aspartic acid and L-glutamic acid such as the esterification conditions, the enantiomeric purity and the nature of the enantiomeric systems (Bolchi, Valoti, Fumagalli et al. 2015).

The simplest and most practiced way to obtain the enantiomers of many $\alpha$-amino acid benzyl esters is the treatment of the unichiral amino acid, as such, with excessive benzyl alcohol. The reaction is usually performed in the presence of little more than 1 equiv of $p$-toluenesulfonic acid, both to catalyze the reaction and to recover the $\alpha$-amino-ester as a crystalline and stable $p$-toluenesulfonate salt, and in a solvent forming a heterogeneous azeotrope with water to remove the water produced by the esterification and thus to make the conversion quantitative (Zervas et al. 1957) (Chart 1). Unbelievably, in the literature procedures, benzene, or even carbon tetrachloride, remains the most used solvent and diethyl ether is widely employed to precipitate the ester salt, although all these solvents are undesirable or banned on any scale production. Furthermore, the optical rotatory power and the melting point of the ester are usually the only analytical data provided besides the spectral data, while the enantiomeric excess is almost never determined although amino acids and their derivatives are long known to racemize with relative ease (Matsuo 1967; Manning 1970; Sato 1970; Bada 1972; Smith 1980; Dhaon 1982; Smith 1983).

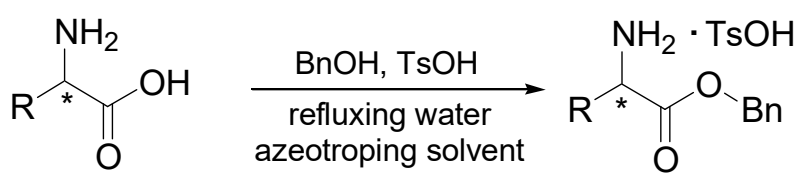

Chart 1. General method to prepare amino acids benzyl esters and to isolate them as $p$-toluenesulfonic acid salts.

After analyzing the $p$-toluenesulfonates of L-aspartic and L-glutamic acid dibenzyl esters and the respective racemates, prepared according to the above long-established procedures (Bergmeier 1993; Zervas 1957), by DSC and chiral HPLC effective in enantioseparation, we have been able to critically revisit the literature preparative procedures based on treatment of the two acidic amino acids with benzyl alcohol and on azeotropic water removal under different conditions. 
To our surprise, we have found that the enantiomeric purity of these diesters is almost always and often wrongly taken for granted, even in works in which the unichirality of the products is a central issue of the investigation. Consequently, water azeotroping solvents are chosen regardless not only of their environmental hazard but also of the potential racemization of the ester. Indeed, toxic or environmentally hazardous solvents, such as benzene and carbon tetrachloride, in which racemization does not take place probably due to the low water azeotrope boiling point, are currently used in laboratory preparations. Alternatively, someone replaces them, on both small and large scale, by higher boiling toluene or benzyl alcohol itself whilst ignoring that extensively racemized aspartic and glutamic dibenzyl esters are formed under these more severe azeotropic reflux conditions.

Within this context, we have successfully proposed the replacement of benzene and carbon tetrachloride with cyclohexane, a solvent considered utilizable on an industrial scale and surely much more acceptable on the basis of overall health, environment, and safety criteria, and of diethyl ether with 2-propanol and ethyl acetate, whose use is recommended (Prat 2016). In refluxing cyclohexane, water is azeotropically removed at relatively low temperature and the conversion of L-aspartic and L-glutamic acid into the respective dibenzyl esters is complete without racemization (Bolchi, Valoti, Fumagalli et al. 2015). These results prompted us to extend our investigation over other amino acids. In order to comparatively evaluate our procedure using cyclohexane, we considered those amino acid benzyl ester tosylates for which literature long provides well-established examples of preparation by treatment with benzyl alcohol and $p$-toluenesulfonic acid in a water azeotroping solvent (see Table 1). Apart from achiral glycine and the previously investigated aspartic and glutamic acid, these are alanine (1), phenylalanine (2), tyrosine (3), phenylglycine (4), valine (5), leucine (6), lysine (7) and serine (8). On the other hand, histidine, asparagine, glutamine and threonine benzyl esters tosylates are just cited as reactants (Kempf 1991; Zhao 2009; Abiko 1983; Nishizawa 1977; Bose 1982) but, to the best of our knowledge, their preparations have never been individually described, while those of tryptophan and arginine are, in different respects, problematic (Arai 1983; Magnus 1989; Biondini 2010; Dorman 1976) and cysteine benzyl ester tosylate is unknown. Of the remaining proline and methionine benzyl esters tosylates, for which one and two preparations with only partial characterizations are reported respectively (Dai 2009; Kawasaki 1980; Fayad 2015), we decided to include methionine (9). Therefore, we have considered the preparation of the benzyl esters tosylates 1a-8a and, in addition, the methionine benzyl ester tosylate 9a, after verifying that literature methods prescribe, for the nine esters, the use of refluxing benzene, toluene, carbon tetrachloride or benzyl alcohol itself regardless of safety and of racemization and provide very few or no analytical data on the enantiomer systems formed by the products and on their enantiomeric composition (Chart 2).<smiles>C[C@H](N)C(=O)OCc1ccccc1</smiles>

$1 a$<smiles>N[C@@H](Cc1ccccc1)C(=O)OCc1ccccc1</smiles>

$2 a$<smiles>N[C@@H](Cc1ccc(O)cc1)C(=O)OCc1ccccc1</smiles>

$3 a$<smiles>NC(C(=O)OCc1ccccc1)c1ccccc1</smiles>

$4 a$<smiles>CC(C)[C@H](N)C(=O)OCc1ccccc1</smiles>

$5 a$<smiles>CC(C)C[C@H](N)C(=O)OCc1ccccc1</smiles>

$6 \mathbf{a}$<smiles>N[C@@H](CCCCN[AsH2])C(=O)OCc1ccccc1</smiles>

$7 \mathbf{a}$<smiles>N[C@@H](CO)C(=O)OCc1ccccc1</smiles>

$8 a$

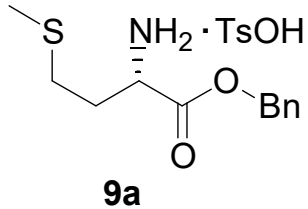

Chart 2. L- or D-amino acid benzyl esters prepared as $p$-toluenesulfonates in cyclohexane.

Here, we report the preparations of the enantiomerically pure benzyl esters $p$-toluenesulfonates $\mathbf{1 a - 9 a}$ by treatment with benzyl alcohol and $p$-toluenesulfonic acid in refluxing cyclohexane together with their melting data and the analytical 
chiral HPLC resolutions of the respective racemates. The same preparations were experimented in refluxing toluene to demonstrate that more or less pronounced racemization instead occurs under these conditions. Benzene and carbon tetrachloride were excluded from our experiments for obvious safety reasons.

\section{Results and discussion}

The state of the art in the preparation of the benzyl esters 1a-9a is summarized in Table 1, where we exemplify what can be found for each aminoacid benzyl ester, in unichiral L or D form, in the literature, namely the solvents used in the esterification reaction, the melting points of the isolated $p$-toluenesulfonates and the respective yields. Briefly, these data can be commented as follows: (a) benzene is the most used solvent and its use still persists, while toluene starts to be extensively employed in the nineties, carbon tetrachloride seems to be abandoned after 2000 and few examples are reported for benzyl alcohol, mainly by some Japanese researchers; (b) concordance between melting points is poor and often these even lack, mostly in the preparations using toluene; (c) the yields are generally very high with the significant exception of 7a in benzyl alcohol and of 9a in benzene; (d) last but the most important thing, the datum concerning the enantiomeric composition is always absent, sometimes subrogated by a questionable comparison between optical rotations. An exception is represented by two patents which denounce the risk of racemization in the preparation of 1a and claim that it can be avoided, in toluene, by adding a small quantity of phenylhydrazine or operating under inert atmosphere (Sato 2004) and, in benzyl alcohol, by applying a reduced pressure which allows water to be distilled off at lower temperature (Hirata 2009).

Therefore, as the enantiomeric purity of the products represents a central issue in these preparations, our investigation, aimed at developing a new procedure to prepare enantiomerically pure 1a-9a without using hazardous solvents, started from this last critical point. The racemates of the nine amino acid benzyl esters tosylates were prepared in refluxing cyclohexane as below described for 1a-9a and chiral HPLC methods were developed to analytically resolve the enantiomers of the benzyl esters possibly as such, namely without derivatization after liberation from the tosylate by simple dichloromethane/aqueous carbonate extraction. Then, supported by this indispensable analytical tool, we prepared 1a-9a. Cyclohexane was selected among usable solvents because the physical properties of its water azeotrope (boiling point, water content, and reciprocal solubility with water) are very similar to those of benzene.

The amino acids were treated with 1.2 equivalents of p-toluenesulfonic acid and 5 equivalents of benzyl alcohol in refluxing cyclohexane for 4 hours so as to azeotropically remove water. In the case of methionine, the reaction was prolonged over night. After cooling to room temperature, ethyl acetate was added to precipitate the ester salt as a white solid. Exceptions to this general procedure were: (a) the use of 2.2 equivalents of p-toluenesulfonic acid for lysine esterification (7a), (b) the conversion of the $p$-toluensulfonate salt $\mathbf{8 a}$, which separates as an oil at the end of the reaction, into the high melting and easy crystallisable hydrochloride and (c) the liberation of L-methionine benzyl ester from the $p$ toluensulfonate salt, which separates as an oily phase at the end of the reaction, and its precipitation as 9a by treatment with $\mathrm{TsOH}$ in ethyl acetate. By the same procedure, we prepared 1a-9a in refluxing toluene.

Table 1. Literature data for compounds 1a-9a.

\begin{tabular}{|c|c|c|c|c|}
\hline $\mathrm{Cpd}^{\mathrm{a}}$ & Solvent $^{\mathrm{b}}$ & $\mathrm{mp}^{\circ} \mathrm{C}$ & yield \% & References \\
\hline 1a & benzene & 113,118 & 84,100 & Gibian, 1961;Tayama, 2012 \\
\hline
\end{tabular}




\begin{tabular}{|c|c|c|c|c|}
\hline & $\mathrm{BnOH}$ & 113,114 & 76 & Winitz, 1956; Izumiya, 1957 \\
\hline & $\mathrm{BnOH}^{\mathrm{c}}$ & - & $84-98$ & Sato, 2004; Hirata, 2009 \\
\hline & toluene & - & 68 & Poras, 1998 \\
\hline \multirow{3}{*}{$\mathbf{2 a}$} & benzene & 165,171 & 95 & Zervas, 1957; Schwarz, 1959; Deal, 1997 \\
\hline & $\mathrm{CCl}_{4}$ & 188 & 96.5 & $\mathrm{Xu}, 2002$ \\
\hline & toluene & - & 79 & Gray, 1991 \\
\hline 3a & benzene & 179 & 88 & Zervas, 1957; Sato, 2008 \\
\hline \multirow{2}{*}{$4 \mathbf{a}$} & benzene & 191 & 98 & Akazome, 2000 \\
\hline & toluene & - & 89 & Llewellyn, 2005 \\
\hline \multirow{3}{*}{$5 \mathbf{a}$} & benzene & 157,160 & 79 & Zervas, 1957; Munegumi, 2012 \\
\hline & $\mathrm{BnOH}$ & 157 & & Izumiya, 1957 \\
\hline & toluene & 156 & 82,91 & Thaqi, 2008; Tagami, 2000 \\
\hline \multirow{3}{*}{$\mathbf{6 a}$} & benzene & 153,160 & 99,100 & Zervas, 1957; Gershon, 1979; Winn, 1997 \\
\hline & $\mathrm{BnOH}$ & 154 & & Izumiya, 1957 \\
\hline & toluene & - & 70,93 & Larbig, 2006; Harju, 2009; Fayad, 2015 \\
\hline \multirow{3}{*}{$7 \mathbf{a}$} & benzene & - & 88 & Takeoka, 2000 \\
\hline & $\mathrm{BnOH}$ & 148 & 13 & Izumiya, 1957; Hachisako, 1999 \\
\hline & toluene & - & & Katsarava, 2007 \\
\hline $\mathbf{8 a}$ & $\mathrm{CCl}_{4}$ & $65,80,94$ & & Folsch, 1959; Boente, 1991; Holden, 2002 \\
\hline \multirow{2}{*}{$9 \mathbf{a}$} & benzene & 133 & 56 & Kawasaki, 1980 \\
\hline & toluene & - & 75 & Fayad, 2015 \\
\hline
\end{tabular}

${ }^{a}$ In a few cases, data are of the other enantiomer. ${ }^{b}$ Used in the esterification reaction at reflux with water collecting Dean-Stark apparatus. ${ }^{c}$ In the presence of additives (hydrazines) or under argon or under reduced pressure.

In Table 2, the results of the preparations in the two solvents are summarized and compared for each amino acid. First, let's consider 1a-8a and then, separately, 9a. The ester salts 1a-8a are obtained in one-step and in very high yield. The esterification of the amino acids 1-8 with benzyl alcohol in refluxing cyclohexane takes place without evident racemization: no traces of the other enantiomer can be detected in the HPLC chromatograms of the benzyl esters liberated from the salts precipitated in very high or quantitative yield at the end of the reaction. Only the benzyl esters of Dphenylglycine and of L-lysine were found to contain a minimum quantity of the opposite enantiomer $(0.6$ and $0.5 \%$ respectively). The tosylates $\mathbf{1 a - 7 a}$ were precipitated by adding ethyl acetate with yields ranging from 88 to $100 \%$, while oily 8a was converted into hydrochloride with an overall process yield of $82 \%$. On the contrary, with the exception of valine, the esterification in toluene was accompanied by extensive racemization. Furthermore, in the case of amino acids with polar alkyl side chain, such as lysine and serine, the chemical yield of the benzylation in toluene was so modest that racemization became a secondary issue and the quantification of the enantiomeric excess not interesting in the isolated benzyl ester salt and problematic in the complex reaction mixture.

Temperature near $100{ }^{\circ} \mathrm{C}$ is known to accelerate the amino acid racemization (Smith 1983; Smith 1989) and indeed our chiral HPLC analyses show how this parameter is important among the reaction conditions: the only $20-30{ }^{\circ} \mathrm{C}$ enhancement for replacement of cyclohexane with higher boiling toluene as a water azeotroping solvent promotes racemization with an extent varying from amino acid to amino acid. In particular, we observed that, in toluene, the racemization increases in the order valine $<$ leucine $<$ alanine $<$ phenylalanine $<$ tyrosine to become quantitative for 
phenylglycine (Table 2). According to several investigators, loss of a proton from the $\alpha$-methine is the initial necessary step in amino acid racemization and, consequently, factors favoring the methine dissociation and stabilizing the incipient carbanion facilitate racemization (Smith 1980). Among these factors, several studies agree that the most important ones are the protonation of the $\alpha$-amine function, the formation of small amounts of the conjugate acid $\left(\mathrm{COOH}_{2}^{+}\right)$promoting enolization, the esterification of the carboxyl group precluding its conversion to $-\mathrm{COO}^{-}$and, discriminant among the various amino acids, the electron-with-drawing capacity of the side chain, better if not $\alpha$-branched (Manning 1970; Bada 1972; Smith 1983). The reported racemizability rankings put phenylglycine first; phenylalanine, alanine and leucine follow in sequence at a great distance, whilst valine is last with practically null racemization (Sato 1970; Smith 1980). Such racemization susceptibility is well linearly correlated to the electronegativity of the side chain, expressed by the Taft's polar constant $\left(\sigma^{*}\right)$, decreasing from phenyl (0.60, Phg) to benzyl (0.225, Phe), methyl (0.00, Ala), $i$-butyl (-0.125, Leu) and $i$-propyl (-0.20, Val) (Sato 1970). Indeed, $i$-propyl appears to be a trade-off between inductive and steric effects ( $\alpha$-branching) and, compared to $i$-butyl, it depresses racemization more than expected from its $\sigma^{*}$ value, only slightly smaller than that of $i$-butyl (Sato 1970). As shown in Table 2 and in Figure 1, the extent of racemization of our corresponding benzyl esters, prepared in toluene, parallels the above ranking and is acceptably correlated to side chain $\sigma^{*}$ with complete racemization of phenylglycine benzyl ester and null racemization of valine benzyl ester at the opposite extremities and intermediate racemizations for phenylalanine, alanine and leucine benzyl esters.

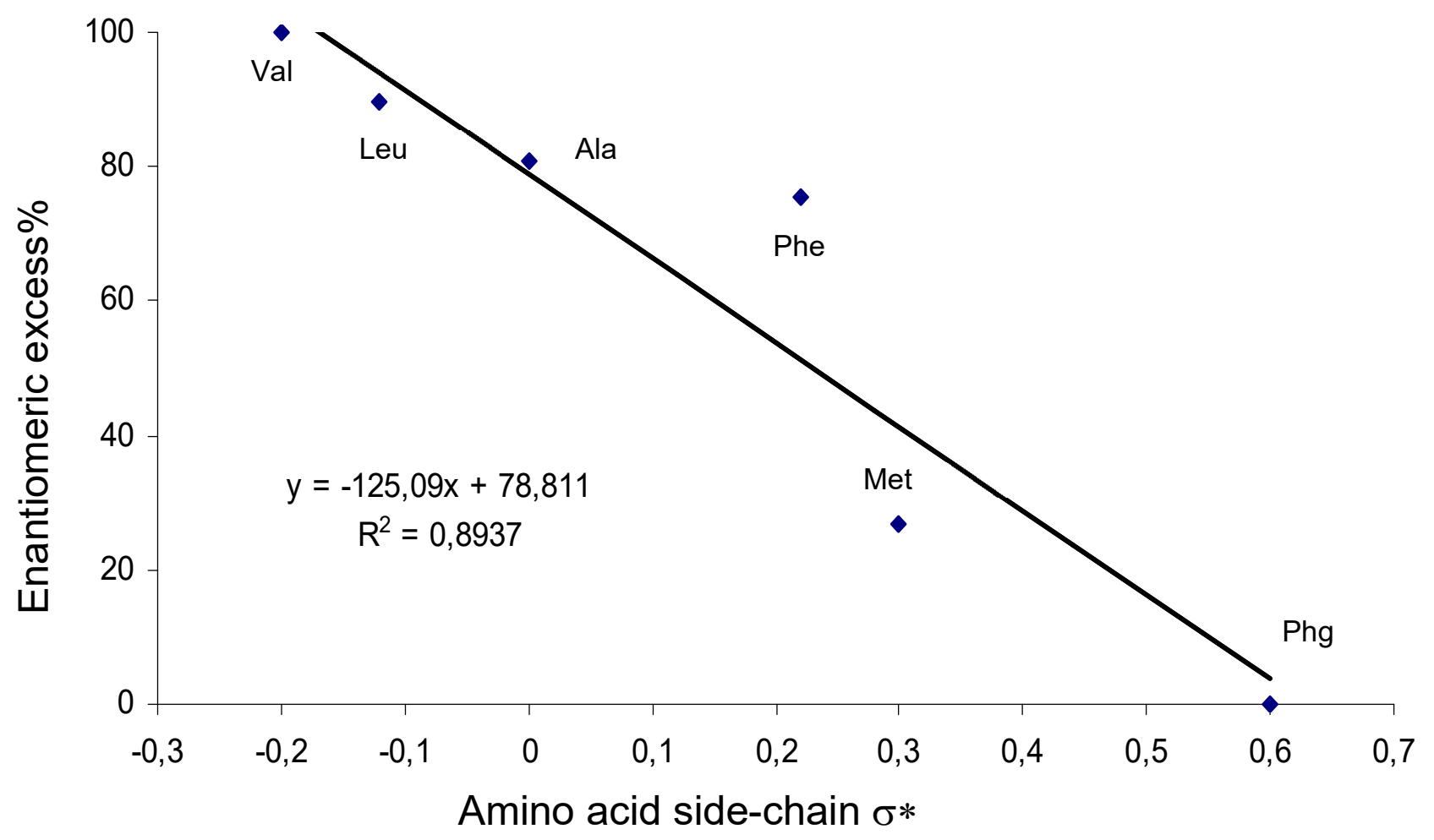

Figure 1. Plot of the enantiomeric excesses of the benzyl esters of valine, leucine, alanine, phenylalanine, methionine and phenylglycine prepared in toluene against the $\sigma^{*}$ values of the amino acids side-chain.

With regard to tyrosine, the literature studies (Liardon 1986) indicate a racemizability slightly lower than that of phenylalanine under alkaline conditions, while we found that its benzyl ester, prepared in toluene, is much more racemized (21.5\% e.e.) than that of phenylalanine (75.3\%). The $p$-hydroxybenzyl side chain has an ionizable phenol function and its electron-with-drawing capacity, unlike the unionizable side chains of the above amino acids, is pH-dependent. Reasonably, at the alkaline pHs of the racemization studies, it is less electronegative than benzyl, because negatively 
charged, and consequently the racemization of tyrosine is lower than that of phenylalanine. In contrast, under the acidic conditions of our esterification, the electron-with-drawing capacity of unionized $p$-hydroxybenzyl exceeds that of benzyl and results in the higher racemization of tyrosine. The higher electron-with-drawing capacity of $p$-hydroxybenzyl compared to benzyl can be inferred, for instance, from the lower basicity of tyrosine and of tyramine in comparison with phenylalanine (Nagai 2008) and phenylethylamine (Martin 1971; Brubacher 1966) respectively.

Coming to the methionine ester $9 \mathrm{a}$, it is to be noted that the older preparation in refluxing benzene has a $56 \%$ yield and is supported by melting point and optical rotation as analytical data (Kawasaki 1980), while the more recent one in refluxing toluene has a 75\% yield but provides neither melting point nor optical rotation (Fayad 2015). In both cases, the enantiomeric excess is an unknown issue. Our results by using cyclohexane are in line with those of the older preparation in benzene. The yield is modest and 9a, which separates as an oil at the end of the reaction, cannot be precipitated as a solid directly from the reaction mixture. It has to be separated, washed, in order to remove benzyl alcohol and $p$ toluenesulfonic acid, and then precipitated as a pure solid from a solution of $p$-toluenesulfonic acid in ethyl acetate. Anyway, chiral HPLC analyses show that both the crude ester and the crystallized salt have high enantiomeric excess (95.6 and 95.7\% respectively), when the preparation is accomplished in refluxing cyclohexane, while a wide racemization ( $27.0 \%$ e.e.) occurs when toluene is used. A sample of $9 \mathbf{a}$, prepared in refluxing benzene according to the literature procedure, exhibited the same enantiomeric excess (95.6\%) as that obtained in cyclohexane. The wide extent of racemization in toluene, near to that of tyrosine and much higher than those of amino acids with alkyl side chains, is consistent with previous observations on the ready racemization of methionine under both acidic (Manning 1970) and alkaline conditions (Smith 1989; Liardon 1986). It is imputable to the thioether group, namely to the electron-withdrawing capacity of the methylthioethyl side-chain, which is sensibly higher than that of alkyl chains. We have not found the $\sigma^{*}$ value of the methionine side-chain in the literature. Therefore, we have considered the reported $\sigma^{*}$ of the following two series of alkyloxy and alkylthio residues: (a) propyloxy (1.57), ethoxymethyl (0.50) and methoxyethyl (0.24) and (b) propylthio (1.38) and ethylthiomethyl (0.56) (Hansch 1979; Hansch 1995). Based on these values and on their parallel disposition, for which $\sigma^{*}$ decreases by shifting both $\mathrm{O}$ and $\mathrm{S}$ towards the end of the three carbon chain, we have extrapolated a near $0.3 \sigma^{*}$ value for the lacking methylthioethyl residue and we have used it to insert methionine into the enantiomeric excess/side-chain plot (Figure 1). As can be seen, the position of methionine benzyl ester results acceptably in line with those of the other amino acids esters thus confirming the correlation of the racemization with the electronwith-drawing capacity of the amino acid side-chain.

We were also interested in gaining information about the nature of the enantiomeric systems formed by the eight amino acid benzyl ester $p$-toluensulfonates in the solid state, because they are isolated by precipitation/crystallization. The DSC analyses show that the enantiomers of the $p$-toluenesulfonates of the benzyl ester of phenylalanine, tyrosine and valine melt at temperatures sensibly higher than the respective racemates thus suggesting that their enantiomeric systems are conglomerates. However, such a suggestion is confirmed only for $\mathbf{3 a}$, whose IR spectrum is superimposable to that of the racemate, and not for $\mathbf{2 a}$ and $\mathbf{5 a}$, which have IR spectra different from those of the racemates. On the other hand, it can be excluded that conglomerates are formed by the enantiomers of the other $p$-toluenesulfonates, which melt about at the same temperature as the corresponding racemates (alanine, phenylglycine, leucine and methionine benzyl ester) or lower (lysine and serine benzyl ester).

Table 2. Comparison between the outcome of the esterification in cyclohexane and in toluene 


\begin{tabular}{|c|c|c|c|c|c|}
\hline \multirow{2}{*}{ Cpd } & \multicolumn{4}{|c|}{ cyclohexane } & \multirow{2}{*}{$\begin{array}{r}\text { toluene } \\
\mathrm{ee} \%{ }^{\mathrm{c}}\end{array}$} \\
\hline & $m p{ }^{\circ} \mathrm{C}^{\mathrm{a}}$ & {$[\alpha]_{\mathrm{D}}{ }^{\mathrm{b}}$} & yield $\%$ & ee $\%{ }^{c}$ & \\
\hline 1a & $109.95(114.33)$ & -3.78 & 92 & 100 & 80.8 \\
\hline $2 a$ & $169.03(148.39)$ & -7.48 & 94 & 100 & 75.3 \\
\hline $3 \mathbf{a}$ & $178.20(150.49)$ & -14.10 & 92 & 100 & 21.5 \\
\hline $4 a$ & 192.59 (193.59) & -35.21 & 95 & 98.8 & $\sim 0$ \\
\hline $5 \mathbf{a}$ & $161.89(123.31)$ & -3.36 & 88 & 100 & 100 \\
\hline $\mathbf{6 a}$ & $159.26(159.33)$ & -2.09 & 100 & 100 & 89.7 \\
\hline $7 \mathbf{a}$ & $162.89(202.14)$ & -5.93 & 85 & 99.0 & $-\mathrm{e}$ \\
\hline $\begin{array}{c}\text { hydrochloride } \\
\text { from } \mathbf{8 a}\end{array}$ & $179.39\left(100.99^{d}\right)$ & -4.67 & 82 & 100 & $-e$ \\
\hline 9a & $129.5(132.1)$ & +0.95 & 40 & 95.7 & 27.0 \\
\hline
\end{tabular}

${ }^{a}$ Melting peak maximum of the enantiomer in the DSC trace and, in brackets, that of the racemate. ${ }^{\mathrm{b}}$ In methanol $(c 1)$ at $25^{\circ} \mathrm{C}$; in water $(c 1)$ at $25{ }^{\circ} \mathrm{C}$ in the case of $7 \mathbf{a}^{\circ}{ }^{\mathrm{c}}$ Determined on the liberated ester by chiral HPLC. ${ }^{\mathrm{d}}$ Of the racemic $p$-toluenesulfonate. ${ }^{\mathrm{e}}$ The ester yield is poor and byproducts are formed.

\section{Conclusions}

In conclusion, we report a new straightforward procedure to obtain a series of enantiomerically pure amino acid benzyl esters in excellent yield by treatment of the amino acid with benzyl alcohol without using water azeotroping solvents that are highly hazardous, such as benzene and carbon tetrachloride, or that cause racemization, such as toluene. We accomplished the esterification in refluxing cyclohexane, which is not hazardous and forms an aqueous azeotrope similar to that of benzene, and precipitated the esters as $p$-toluenesulfonates by adding ethyl acetate instead of diethyl ether. The enantiopurity of the amino acids benzyl esters prepared in refluxing cyclohexane and the racemization of the same esters prepared in refluxing toluene were demonstrated by chiral HPLC analysis. The racemization is favored by the high boiling temperature of toluene and increases with the electronegativity of the amino acid side chain, as indicated by the good correlation found between enantiomeric excess and Taft's polar substituent constant of the amino acid side chain. Methionine, tyrosine and phenylglycine benzyl esters showed the highest susceptibility to racemize.

\section{Materials and methods}

${ }^{1} \mathrm{H}$ NMR spectra were recorded on a Varian Gemini 300 operating at $300 \mathrm{MHz}$. Chemical shifts are reported in ppm relative to residual solvent $\left(\mathrm{CHCl}_{3}\right.$, DMSO and methanol) as internal standard. The melting points were determined by DSC analysis and the melting peak maximum is reported for each compound. The DSC curves were recorded and integrated with the aid of a TA Instruments DSC 2010 apparatus. Optical rotations were determined in a $1 \mathrm{dm}$ cell of 5 $\mathrm{mL}$ capacity by using a Perkin-Elmer 241 polarimeter. Enantiomeric excesses were determined by chiral HPLC on 150 $\mathrm{mm} \times 4.6 \mathrm{~mm}$ i.d. columns at 210 or $220 \mathrm{~nm}$.

\section{General procedure for the preparation of 1a-9a}


The esterifications were carried out on L amino acids with the exception of phenylglycine, the D enantiomer of which was used. A mixture of amino acid $(0.05 \mathrm{~mol}), p$-toluenesulfonic acid $(0.06 \mathrm{~mol})$, benzyl alcohol $(0.25 \mathrm{~mol})$ and cyclohexane $(30 \mathrm{~mL})$ was refluxed for $4 \mathrm{~h}$ by using a Dean-Stark apparatus to separate water that was azeotroped out as it formed. The reaction mixture was cooled to room temperature and ethyl acetate $(80 \mathrm{~mL})$ was added. After stirring for $1 \mathrm{~h}$, the precipitate was collected by filtration and dried to give the corresponding benzyl ester $p$-toluenesulfonate as a white solid. According to this procedure, the amino acids 1-6 were converted into the corresponding benzyl ester $p$-toluenesulfonates 1a-6a. The benzylation of 7 was accomplished in the same manner but in the presence of more $p$-toluenesulfonic acid $(0.11 \mathrm{~mol})$ to give the di- $p$-toluenesulfonate $7 \mathbf{a}$ as a white solid. The $p$-toluenesulfonate $8 \mathbf{a}$ separated at the end of the reaction as an oil; instead of adding ethyl acetate, the supernatant was removed, the oily phase was washed with cyclohexane and then poured into dichloromethane/aqueous $\mathrm{Na}_{2} \mathrm{CO}_{3}$. After removing the water layer and evaporating dichloromethane, the residue was treated with hydrochloric methanol to give the corresponding hydrochloride as a white solid. The benzylation of 9 was prolonged over night and, at the end of the reaction, 9a separated as an oil, which was poured into dichloromethane/water. After removing the organic layer, the water phase was made alkaline with $\mathrm{NaHCO}_{3}$ and extracted with ethyl acetate. The organic extract was concentrated and the resultant residue converted in $p$ toluenesulfonate by treatment with a slight excess of $p$-toluenesulfonic acid in ethyl acetate.

The racemic benzyl esters were prepared in the same manner as the enantiomeric forms and all the $p$-toluenesulfonates precipitated as white solids by adding ethyl acetate, excluding only that of methionine benzyl ester, which was recovered as described for $9 \mathbf{a}$.

\section{L-Alanine benzyl ester $p$-toluenesulfonate (1a)}

Obtained as a white solid in $92 \%$ yield: $\mathrm{mp} 109.95{ }^{\circ} \mathrm{C} ;[\alpha]_{\mathrm{D}}{ }^{25}=-3.78(c 1, \mathrm{MeOH}) ; 100 \%$ e.e. (determined by HPLC analysis on a Phenomenex Lux $3 \mu$ Cellulose-1 column; hexane $\left./ \mathrm{PrOH} 9 / 1,1 \mathrm{~mL} / \mathrm{min} ; t_{\mathrm{R}}=8.0 \mathrm{~min}\right) ;{ }^{1} \mathrm{H} \mathrm{NMR}(300 \mathrm{MHz}$, $\left.\mathrm{CDCl}_{3}\right) \delta 1.46(\mathrm{~d}, J=7.6 \mathrm{~Hz}, 3 \mathrm{H}), 2.30(\mathrm{~s}, 3 \mathrm{H}), 4.04(\mathrm{~m}, 1 \mathrm{H}), 4.99(\mathrm{~d}, J=12.3 \mathrm{~Hz}, 1 \mathrm{H}), 5.08(\mathrm{~d}, J=12.3 \mathrm{~Hz}, 1 \mathrm{H}), 7.06$ $(\mathrm{d}, J=7.6 \mathrm{~Hz}, 2 \mathrm{H}), 7.22-7.29(\mathrm{~m}, 5 \mathrm{H}), 7.72(\mathrm{~d}, J=7.6 \mathrm{~Hz}, 2 \mathrm{H}), 8.24$ (br s, 3H).

\section{rac-Alanine benzyl ester $p$-toluenesulfonate}

$\mathrm{Mp} 114.33{ }^{\circ} \mathrm{C}$; HPLC analysis as for 1a: the D enantiomer corresponds to the second eluted peak $\left(t_{\mathrm{R}}=8.7 \mathrm{~min}\right)$.

\section{L-Phenylalanine benzyl ester $p$-toluenesulfonate (2a)}

Obtained as a white solid in 94\% yield: $\mathrm{mp} 169.03{ }^{\circ} \mathrm{C} ;[\alpha]_{\mathrm{D}}{ }^{25}=-7.48(c$ 1, MeOH); 100\% e.e. (determined by HPLC analysis on a Phenomenex Lux $3 \mu$ Cellulose-1 column; hexane/ $\left.\mathrm{PrOH} 9 / 1,1 \mathrm{~mL} / \mathrm{min} ; t_{\mathrm{R}}=9.2 \mathrm{~min}\right) ;{ }^{1} \mathrm{H} \mathrm{NMR}(300 \mathrm{MHz}$, $\left.\mathrm{CDCl}_{3}\right) \delta 2.30(\mathrm{~s}, 3 \mathrm{H}), 3.12(\mathrm{~m}, 1 \mathrm{H}), 3.23(\mathrm{~m}, 1 \mathrm{H}), 4.32(\mathrm{~m}, 1 \mathrm{H}), 4.88(\mathrm{~d}, J=12.3 \mathrm{~Hz}, 1 \mathrm{H}), 4.99(\mathrm{~d}, J=12.3 \mathrm{~Hz}, 1 \mathrm{H})$, 6.95-7.26 (m, $12 \mathrm{H}), 7.70(\mathrm{~d}, J=7.6 \mathrm{~Hz}, 2 \mathrm{H}), 8.27$ (br s, $3 \mathrm{H})$.

\section{rac-Phenylalanine benzyl ester $p$-toluenesulfonate}

Mp $148.39^{\circ} \mathrm{C}$; HPLC analysis as for $\mathbf{2 a}$ : the D enantiomer corresponds to the second eluted peak $\left(t_{\mathrm{R}}=10.9 \mathrm{~min}\right)$.

\section{L-Tyrosine benzyl ester p-toluenesulfonate (3a)}

Obtained as a white solid in $92 \%$ yield: $\mathrm{mp} 178.20^{\circ} \mathrm{C} ;[\alpha]_{\mathrm{D}}{ }^{25}=-14.10(c 1, \mathrm{MeOH}) ; 100 \%$ e.e. (determined by HPLC analysis on a Phenomenex Lux $3 \mu$ Amylose-2 column; hexane $\left./ \mathrm{PrOH} 95 / 5,1 \mathrm{~mL} / \mathrm{min} ; t_{\mathrm{R}}=18.5 \mathrm{~min}\right) ;{ }^{1} \mathrm{H} \mathrm{NMR}(300$ 
MHz, DMSO- $\left.d_{6}\right) \delta 2.27(\mathrm{~s}, 3 \mathrm{H}), 2.98(\mathrm{~m}, 2 \mathrm{H}), 4.26(\mathrm{~m}, 1 \mathrm{H}), 5.14(\mathrm{~s}, 2 \mathrm{H}), 6.66(\mathrm{~d}, J=7.6 \mathrm{~Hz}, 2 \mathrm{H}), 6.93(\mathrm{~d}, J=7.6$ Hz, 2 H), 7.09 (s, 2 H), 7.26 (s, 2 H), 7.34 (s, 3 H), 7.48 (d, J= 7.6 Hz, 2 H), 8.37 (br s, 3 H), 9.38 (br s, 1 H).

\section{rac-Tyrosine benzyl ester $p$-toluenesulfonate}

Mp $150.49^{\circ} \mathrm{C}$; HPLC analysis as for 3a: the D enantiomer corresponds to the second eluted peak $\left(t_{\mathrm{R}}=20.0 \mathrm{~min}\right)$.

\section{D-Phenylglycine benzyl ester $p$-toluenesulfonate (4a)}

Obtained as a white solid in 95\% yield: $\mathrm{mp} 192.59{ }^{\circ} \mathrm{C} ;[\alpha]_{\mathrm{D}}{ }^{25}=-35.21(c 1, \mathrm{MeOH}) ; 98.8 \%$ e.e. (determined by HPLC analysis on a Phenomenex Lux $3 \mu$ Cellulose-1 column; hexane/MeOH/EtOH 79/13/7, $1 \mathrm{~mL} / \mathrm{min} ; t_{\mathrm{R}}=7.25 \mathrm{~min}$ ); ${ }^{1} \mathrm{H}$ $\operatorname{NMR}\left(300 \mathrm{MHz}, \mathrm{CDCl}_{3}\right) \delta 2.30(\mathrm{~s}, 3 \mathrm{H}), 4.94(\mathrm{~d}, J=12.3 \mathrm{~Hz}, 1 \mathrm{H}), 5.00(\mathrm{~d}, J=12.3 \mathrm{~Hz}, 1 \mathrm{H}), 5.13(\mathrm{~m}, 1 \mathrm{H}), 7.02(\mathrm{~m}, 2$ H), 7.14-7.30 (m, $10 \mathrm{H}), 7.51$ (d, $J=8.2 \mathrm{~Hz}, 2 \mathrm{H}), 8.70$ (br s, $3 \mathrm{H})$.

\section{rac-Phenylglycine benzyl ester $p$-toluenesulfonate}

Mp $193.59^{\circ} \mathrm{C}$; HPLC analysis as for 4a: the L enantiomer corresponds to the first eluted peak $\left(t_{\mathrm{R}}=6.6 \mathrm{~min}\right)$.

\section{L-Valine benzyl ester $p$-toluenesulfonate (5a)}

Obtained as a white solid in $88 \%$ yield: $\mathrm{mp} 161.89{ }^{\circ} \mathrm{C} ;[\alpha]_{\mathrm{D}}{ }^{25}=-3.36(c 1, \mathrm{MeOH}) ; 100 \%$ e.e. (determined by HPLC analysis on a Phenomenex Lux $3 \mu$ Cellulose-1 column; hexane $\left./ \mathrm{PrOH} 9 / 1,1 \mathrm{~mL} / \mathrm{min} ; 220 \mathrm{~nm}, t_{\mathrm{R}}=5.3 \mathrm{~min}\right) ;{ }^{1} \mathrm{H} \mathrm{NMR}$ $\left(300 \mathrm{MHz}, \mathrm{CDCl}_{3}\right) \delta 0.88(\mathrm{pt}, J=6.4 \mathrm{~Hz}, 6 \mathrm{H}), 2.18(\mathrm{~m}, 1 \mathrm{H}), 2.31(\mathrm{~s}, 3 \mathrm{H}), 3.90(\mathrm{~m}, 1 \mathrm{H}), 5.01(\mathrm{~d}, J=12.3 \mathrm{~Hz}, 1 \mathrm{H})$, $5.12(\mathrm{~d}, J=12.3 \mathrm{~Hz}, 1 \mathrm{H}), 7.09$ (d, $J=8.2 \mathrm{~Hz}, 2 \mathrm{H}), 7.28$ (s, $5 \mathrm{H}), 7.75(\mathrm{~d}, J=8.2 \mathrm{~Hz}, 2 \mathrm{H}), 8.23$ (br s, $3 \mathrm{H})$.

rac-Valine benzyl ester $p$-toluenesulfonate

Mp $123.31{ }^{\circ} \mathrm{C}$; HPLC analysis as for 5a: the D enantiomer corresponds to the second eluted peak $\left(t_{\mathrm{R}}=5.9 \mathrm{~min}\right)$.

\section{L-Leucine benzyl ester p-toluenesulfonate (6a)}

Obtained as a white solid in quantitative yield: $\mathrm{mp} 159.26{ }^{\circ} \mathrm{C} ;[\alpha]_{\mathrm{D}}^{25}=-2.09(c 1, \mathrm{MeOH}) ; 100 \%$ e.e. (determined by HPLC analysis on a Phenomenex Lux $3 \mu$ Amylose-2 column; hexane $/$ PrOH 95/5, $\left.1 \mathrm{~mL} / \mathrm{min} ; t_{\mathrm{R}}=8.3 \mathrm{~min}\right)$; ${ }^{1} \mathrm{H}$ NMR $\left(300 \mathrm{MHz}, \mathrm{CDCl}_{3}\right) \delta 0.74(\mathrm{pt}, J=5.3 \mathrm{~Hz}, 6 \mathrm{H}), 1.66(\mathrm{~m}, 3 \mathrm{H}), 2.30(\mathrm{~s}, 3 \mathrm{H}), 3.96(\mathrm{~m}, 1 \mathrm{H}), 5.02(\mathrm{~d}, J=12.3 \mathrm{~Hz}, 1 \mathrm{H})$, $5.11(\mathrm{~d}, J=12.3 \mathrm{~Hz}, 1 \mathrm{H}), 7.07$ (d, $J=8.2 \mathrm{~Hz}, 2 \mathrm{H}), 7.27$ (s, $5 \mathrm{H}), 7.74(\mathrm{~d}, J=8.2 \mathrm{~Hz}, 2 \mathrm{H}), 8.26$ (br s, $3 \mathrm{H})$.

rac-Leucine benzyl ester $p$-toluenesulfonate

Mp $159.33{ }^{\circ} \mathrm{C}$; HPLC analysis as for $6 \mathbf{a}$ : the D enantiomer corresponds to the first eluted peak $\left(t_{\mathrm{R}}=7.70 \mathrm{~min}\right)$.

\section{L-Lysine benzyl ester di-p-toluenesulfonate (7a)}

Obtained as a light yellow solid in $85 \%$ yield: mp $162.89^{\circ} \mathrm{C} ;[\alpha]_{\mathrm{D}}^{25}=-5.93\left(c 1, \mathrm{H}_{2} \mathrm{O}\right) ; 99.0 \%$ e.e. (determined by HPLC analysis of the liberated and $N, N$ '-dibenzoylated amino acid on a Phenomenex Lux $3 \mu$ Cellulose-1 column; hexane/iPrOH 8/2, $\left.2 \mathrm{~mL} / \mathrm{min} ; t_{\mathrm{R}}=14.1 \mathrm{~min}\right) ;{ }^{1} \mathrm{H} \mathrm{NMR}\left(300 \mathrm{MHz}, \mathrm{CD}_{3} \mathrm{OD}\right) \delta 1.34-1.58(\mathrm{~m}, 2 \mathrm{H}), 1.66(\mathrm{~m}, 2 \mathrm{H}), 1.92(\mathrm{~m}, 2 \mathrm{H}), 2.36(\mathrm{~s}$, $6 \mathrm{H}), 2.86(\mathrm{t}, J=7.6 \mathrm{~Hz}, 2 \mathrm{H}), 4.09(\mathrm{t}, J=6.4 \mathrm{~Hz}, 1 \mathrm{H}), 5.24(\mathrm{~d}, J=12.3 \mathrm{~Hz}, 1 \mathrm{H}), 5.31(\mathrm{~d}, J=12.3 \mathrm{~Hz}, 1 \mathrm{H}), 7.22(\mathrm{~d}, J$ $=8.2 \mathrm{~Hz}, 4 \mathrm{H}), 7.37(\mathrm{~m}, 5 \mathrm{H}), 7.70(\mathrm{~d}, J=8.2 \mathrm{~Hz}, 4 \mathrm{H})$. 
Mp $202.14^{\circ} \mathrm{C}$; HPLC analysis as for $7 \mathbf{a}$ : the $N, N^{\prime}$-dibenzoylated D enantiomer corresponds to the first eluted peak $\left(t_{\mathrm{R}}=\right.$ $5.0 \mathrm{~min})$.

\section{L-Serine benzyl ester $p$-toluenesulfonate (8a)}

Obtained as an oil $\left[{ }^{1} \mathrm{H}\right.$ NMR $\left(300 \mathrm{MHz}, \mathrm{CDCl}_{3}\right) \delta 2.25(\mathrm{~s}, 3 \mathrm{H}), 3.85(\mathrm{dd}, J=4.7,12.9 \mathrm{~Hz}, 1 \mathrm{H}), 3.99(\mathrm{dd}, J=2.9,12.9$ $\mathrm{Hz}, 1 \mathrm{H}), 4.09$ (m, 1H), 4.99 (d, $J=12.3 \mathrm{~Hz}, 1 \mathrm{H}), 5.05(\mathrm{~d}, J=12.3 \mathrm{~Hz}, 1 \mathrm{H}), 7.00(\mathrm{~d}, J=7.6 \mathrm{~Hz}, 2 \mathrm{H}), 7.24(\mathrm{~m}, 5 \mathrm{H}), 7.67$ $(\mathrm{d}, J=7.6 \mathrm{~Hz}, 2 \mathrm{H}), 8.06$ (br s, $3 \mathrm{H})]$ and then converted into the white solid hydrochloride in $82 \%$ yield: $\mathrm{mp} 179.39{ }^{\circ} \mathrm{C}$; $[\alpha]_{\mathrm{D}}{ }^{25}=-4.67(c 1, \mathrm{MeOH}) ; 100 \%$ e.e. (determined by HPLC analysis on a Phenomenex Lux $3 \mu$ Amylose-2 column, $150 \mathrm{~mm} \times 4.6 \mathrm{~mm}$ i.d.; hexane $\left./ \mathrm{iPrOH} 9 / 1 ; 2 \mathrm{~mL} / \mathrm{min} ; 220 \mathrm{~nm}, t_{\mathrm{R}}=9.6 \mathrm{~min}\right) ;{ }^{1} \mathrm{H} \mathrm{NMR}\left(300 \mathrm{MHz}, \mathrm{DMSO}-d_{6}\right) \delta 3.85(\mathrm{~m}$, 2H), $4.18(\mathrm{~m}, 1 \mathrm{H}), 5.22(\mathrm{~s}, 2 \mathrm{H}), 5.65$ (br s, 1H), 7.28-7.52 (m, 5H), 8.65 (br s, 3H).

\section{rac-Serine benzyl ester $p$-toluenesulfonate}

Mp $100.99^{\circ} \mathrm{C}$; HPLC analysis as for 8a: the D enantiomer corresponds to the second eluted peak $\left(t_{\mathrm{R}}=11.2 \mathrm{~min}\right)$.

\section{L-Methionine benzyl ester p-toluenesulfonate (9a)}

Obtained as a white solid in $40 \%$ yield: m.p. $=129.51^{\circ} \mathrm{C} ;[\alpha]_{\mathrm{D}}{ }^{25}=+0.95(c$ 1, MeOH); 95.7\% e.e. (determined by HPLC analysis on a Phenomenex Lux $3 \mu$ Amylose-2 column, $150 \mathrm{~mm} \times 4.6 \mathrm{~mm}$ i.d.; hexane/iPrOH 80/20; $1 \mathrm{~mL} / \mathrm{min} ; 210 \mathrm{~nm}$, $\left.t_{\mathrm{R}}=11.3 \mathrm{~min}\right) ;{ }^{1} \mathrm{H}$ NMR $\left(300 \mathrm{MHz}, \mathrm{CDCl}_{3}\right) \delta 1.84(\mathrm{~s}, 3 \mathrm{H}), 2.10(\mathrm{~m}, 2 \mathrm{H}), 2.30(\mathrm{~s}, 3 \mathrm{H}), 2.43(\mathrm{~m}, 2 \mathrm{H}), 4.14(\mathrm{~m}, 1 \mathrm{H}), 5.00$ $(\mathrm{d}, J=12.3 \mathrm{~Hz}, 1 \mathrm{H}), 5.12(\mathrm{~d}, J=12.3 \mathrm{~Hz}, 1 \mathrm{H}), 7.08(\mathrm{~d}, J=7.0 \mathrm{~Hz}, 2 \mathrm{H}), 7.24-7.30(\mathrm{~m}, 5 \mathrm{H}), 7.73(\mathrm{~d}, J=7.0 \mathrm{~Hz}, 2 \mathrm{H}), 8.35$ (br s, 3H).

rac-Methionine benzyl ester $p$-toluenesulfonate

Mp $132.1^{\circ} \mathrm{C}$; HPLC analysis as for 9a: the D enantiomer corresponds to the first eluted peak $\left(t_{\mathrm{R}}=8.9 \mathrm{~min}\right)$.

\section{Compliance with ethical standards}

Conflict of interest The authors declare that they have no conflict of interest.

Ethical approval This article does not contain any studies with human partecipants or animals performed by any of the authors.

Informed consent Informed consent was obtained from all individual partecipants included in the study.

\section{References}

Abiko T, Sekino H (1983) Synthesis of the nonatriacontapeptide corresponding to the entire amino acid sequence of calf thymosin $\beta_{8}$ and its effect on the impaired T-cell subsets in patients with Lupus Nephritis. Chem Pharm Bull $31: 1320-1329$. 
Akazome M, Ueno Y, Ooiso H, Ogura K (2000) Enantioselective inclusion of methyl phenyl sulfoxides and benzyl methyl sulfoxides by $(R)$-phenylglycyl- $(R)$-phenylglycine and the crystal structures of the inclusion cavities. J Org Chem 65:68-76.

Arai I, Muramatsu I (1983) A simple and convenient method for esterification of tryptophan and other amino acids. J Org Chem 48:121-123.

Bada J L (1972) Kinetics of racemization of amino acids as a function of pH. J Amer Chem Soc 94:1371-1373.

Bergmeier S C, Cobas A A, Rapoport H (1993) Chirospecific synthesis of (1S,3R)-1-amino-3(hydroxymethyl)cyclopentane, precursor of carbocyclic nucleoside synthesis. Dieckmann cyclization with an alphaamino acid. J Org Chem 58:2369-2376.

Biondini D, Brinchi L, Germani R, Goracci L, Savelli G (2010) Esterification of unprotected $\alpha$-amino acids in ionic liquids as the reaction media. Lett Org Chem 7:39-44.

Boente M I P, Kirby G, Patrick G L, Robins D J (1991) Biosynthesis of hyalodendrin and didethiobis(methylthio) hyalodendrin, sulfur-containing 2,5-dioxopiperazines of the 3S,6S series. J Chem Soc Perkin Trans 1:1283-1290.

Bolchi C, Pallavicini M, Rusconi C, Diomede L, Ferri N, Corsini A, Fumagalli L, Pedretti A, Vistoli G, Valoti E (2007) Peptidomimetic inhibitors of farnesyltransferase with high in vitro activity and significant cellular potency. Bioorg Med Chem Lett 17:6192-6196.

Bolchi C, Valoti E, Fumagalli L, Straniero V, Ruggeri P, Pallavicini M (2015) Enantiomerically pure dibenzyl esters of L-aspartic and L-glutamic acid. Org Process Res Dev 19:878-883.

Bolchi C, Valoti E, Gotti C, Fasoli F, Ruggeri P, Fumagalli L, Binda M, Mucchietto V, Sciaccaluga M, Budriesi R, Fucile S, Pallavicini M (2015) Chemistry and pharmacology of a series of unichiral analogues of 2-(2-pyrrolidinyl) -1,4-benzodioxane, prolinol phenyl ether, and prolinol 3-pyridyl ether designed as $\alpha 4 \beta 2$-nNicotinic acetylcholine receptor agonists. J Med Chem 58:6665-6677.

Bose A K, Manhas M S, Vincent J E, Gala K, Fernandez I F (1982) N-Unsubstituted $\beta$-lactams from $\beta$-hydroxy- $\alpha$ amino acids. Facile preparation of intermediates for isocephalosporins. J Org Chem 47:4075-4081.

Brubacher L J, Bender M L (1966) The preparation and properties of trans-cinnamoyl-papain. J Am Chem Soc 88:5871-5880.

Cerić H, Šindler-Kulyk M, Kovačević M, Perić M, Živković A (2010) Azetidinone-isothiazolidinones: stereoselective synthesis and antibacterial evaluation of new monocyclic beta-lactams. Bioorg Med Chem 18:30533058 .

Dai N, Etzkorn F A (2009) Cis-trans proline isomerization effects on collagen triple-helix stability are limited. J Am Chem Soc 131:13728-13732.

Dhaon M K, Olsen R K, Ramasamy K (1982) Esterification of N-protected alpha-amino acids with alcohol/carbodiimide/4-(Dimethylamino)-pyridine. Racemization of aspartic and glutamic acid derivatives. J Org Chem 47:1962-1965.

Deal K A, Welch M J (1997) Effect of stereochemistry on the clearance mechanism of ${ }^{111} \operatorname{In}(\mathrm{III})$-labeled D- or Lbenzyldiethylenetriaminepentaacetic acid. J Med Chem 40:3986-3989.

Dorman L C, Cheng R C (1976) Fibrinogen peptide derivatives, US 3966701.

Fayad A A, Pubill-Ulldemolins C, Sharma S V, Day D, Goss R J M (2015) A one-pot synthesis of symmetrical and unsymmetrical dipeptide ureas. Eur J Org Chem 2015:5603-5609.

Fölsch G (1959) Synthesis of phosphopeptides. Acta Chem Scand 13:1407-1421.

Gershon H, Krull I S (1979) Dipeptides of $O$-methyl-L-threonine as potential antimalarials. J Med Chem 22:877879. 
Gibian H, Schroeder E (1961) Peptide syntheses.III:Syntheses of arginine-containing peptides. Justus Liebigs Ann Chem 642:145-162.

Gray C J, Quibell M, Jiang K L, Baggett N (1991) Synthesis and spectroscopic properties of azaglutamine amino acid and peptide derivatives. Synthesis 141-146.

Hachisako H, Murata Y, Ihara H (1999) Supramolecular receptors from $\alpha$-amino acid-derived lipids. J Chem Soc Perkin Trans 2 2569-2577.

Hansch C, Leo A (1979) Substituent constants for correlation analysis in chemistry and biology. Wiley, New York, pp 106-107.

Hansch C, Leo A, Hoekman D (1995) Exploring QSAR. Hydrophobic, steric and electronic Constants. American Chemical Society, Washington, p 252.

Harju K, Manevski N, Yli-Kauhaluoma J (2009) Microwave-assisted synthesis of pyridylpyrroles from $N$-acylated amino acids. Tetrahedron 65:9702-9706.

Hirata N (2009) Process for the production of optically active alpha-amino acid benzyl ester. EP, 2062873 A1.

Holden K G, Mattson M N, Cha K H, Rapoport H (2002) Synthesis of chiral pilocarpine analogues via a C-8 ketone intermediate. J Org Chem 67:5913-5918.

Izumiya N, Makisumi S (1957) Synthesis of aminoacid benzyl ester $p$-toluenesulfonates. Nippon Kagaku Zasshi 78:662-664.

Katsarava R, Tugushu D, Gomurashvili Z D (2007) Poly(ester urea) polymers and methods of use. WO 2007/050415 A2.

Kawasaki K, Kawasaki C, Maeda M, Okada Y (1980) Synthesis of tetradecapeptide corresponding to sequence 90103 of bovine adrenodoxin. Chem Pharm Bull 28:2105-2115.

Kempf D J, Rosenberg S H, Plattner J J, Shan H L, De Biswanath (1991) Heterocyclic renin inhibitors. US, 4994477. Larbig G, Schmidt B (2006) Synthesis of tetramic and tetronic acids as beta-secretase inhibitors. J Comb Chem $8: 480-490$.

Liardon R, Ledermann S (1986) Racemization kinetics of free and protein-bound amino acids under moderate alkaline treatment. J Agric Food Chem 34:557-565.

Liu J, Wu G, Cui G, Wang W-X, Zhao M, Wang C, Zhang Z, Peng S (2007) A new class of anti-thrombosis hexahydropyrazino-[1',2':1,6]pyrido-[3,4b]-indole-1,4-dions: design, synthesis, $\log K$ determination, and QSAR analysis. Bioorg Med Chem 15:5672-5693.

Liu J, Zhao M, Qian K, Zhang X, Lee K-H, Wu J, Liu Y-N, Peng S (2010) Benzyl 1,2,3,5,11,11a-hexahydro-3,3dimethyl-1-oxo-6H-imidazo[3',4':1,2]pyridine[3,4-b]indole-2-substituted acetates: one-pot-preparation, antitumor activity, docking toward DNA and 3D QSAR analysis. Bioorg Med Chem 18:1910-1917.

Llewellyn D B, Arndtsen B A (2005) Synthesis of a library of chiral alpha-amino acid-based borate counteranions and their application to copper catalyzed olefin cyclopropanation. Tetrahedron: Asymmetry 16:1789-1799.

Magnus P, Ladlow M, Kim C S, Boniface P (1989) Use of the Barton decarboxylation procedure in indole alkaloid chemistry. Heterocycles 28:951-956.

Manning J M (1970) Determination of D- and L-amino acid residues in peptides. Use of tritiated hydrochloric acid to correct for racemization during acid hydrolysis. J Amer Chem Soc 92:7449-7454.

Mao Z-Y, Geng H, Zhang T-T, Ruan Y-P, Ye J-L, Huang P-Q (2016) Stereodivergent and enantioselective total syntheses of isochaetominines A-C and four pairs of isochaetominine C enantiomers: a six-step approach. Org Chem Front 3:24-37. 
Martin R B (1971) Zwitterion formation upon deprotonation in L-3,4-dihydroxyphenylalanine and other phenolic amines. J Phys Chem 75:2657-2661.

Matsuo H, Kawazoe Y, Sato M, Ohnishi M, Tatsuno T (1967) Studies on the racemization of amino acids and their derivatives I. Chem Pharm Bull 15:391-398.

Munegumi T, Wakatsuki A, Takahashi Y (2012) Enantiomeric resolution of $p$-toluenesulfonate of valine benzyl ester by preferential crystallization. Chirality 24:188-192.

Nagai H, Kuwabara K, Carta G (2008) Temperature dependence of dissociation constants of several amino acids. J Chem Eng Data 53:619-627.

Nishizawa R, Saino T (1977) Synthesis and structure-activity relationships of bestatin analogues, inhibithors of aminopeptidase B. J Med Chem 20:510-515.

Pallavicini M, Bolchi C, Fumagalli L, Piccolo O, Valoti E (2010) A highly efficient method for the alpha,betadehydrogenation of alpha-amino esters and alpha-amino-beta diesters. Tetrahedron Lett 51:5540-5542.

Poras H, Kunesch G (1998) Synthesis and in vitro antibacterial activity of catechol-spiramycin conjugates. J Antibiotics 51:786-794.

Prat D, Wells A, Hayler J, Sneddon H, McElroy R C, Abou-Shehada S, Dunn P J (2016) CHEM21 selection guide of classical- and less classical-solvents. Green Chem 18:288-296.

Sato M, Tatsuno T, Matsuo H (1970) Studies on the racemization of amino acids and their derivatives III. Chem Pharm Bull 18:1794-1798.

Sato A, Yoshida M, Hara S (2008) Primary amino acid lithium salt as a catalyst for asymmetric Michael addition of isobutyraldehyde with beta-nitroalkenes. Chem Commun 6242-6244.

Sato H, Ohno T, Iwata S (2004) Optically active amino acid derivatives and processes for the preparation of the same. US, $6706916 \mathrm{~B} 1$.

Schwarz H, Arakawa K (1959) The use of p-nitrobenzyl esters in peptide synthesis. J Am Chem Soc 81:5691-5695. Tagami Y, Katsura T, Itaya N (2000) Process for producing L-valine benzyl ester p-toluenesulfonate. EP, 0985658 A1.

Smith G G, Evans R C (1980) The effect of structure and conditions on the rate of racemization of free and bound amino acids. In: Hare P E, Hoering T C, King K Jr (eds) Biogeochemistry of amino acids. Wiley, New York, pp 257-282.

Smith G G, Sivakua T (1983) Mechanism of the racemization of amino acids. Kinetics of racemization of arylglycines. J Org Chem 48:627-634.

Smith G G, Reddy G V (1989) Effect of the side chain on the racemization of amino acids in aqueous solution. J Org Chem 54:4529-4535.

Takeoka S, Mori K, Ohkawa H, Sou K, Tsuchida E (2000) Synthesis and assembly of poly(ethylene glycol)-lipids with mono-, di-, and tetraacyl chains and a poly(ethylene glycol) chain of various molecular weights. J Am Chem Soc 122:7927-7935.

Tayama E, Igarashi T, Iwamoto H, Hasegawa E (2012) Asymmetric $\alpha$-2-tosylethenylation of N,N-dialkyl-L-amino acid esters via the formation of non-racemic ammonium enolates. Org Biomol Chem 10:339-345.

Tekkam s, Johnson J L, Jonnalagadda S C, Mereddy V R (2013) Concise synthesis of $\alpha$-methylene- $\beta$-hydroxy- $\gamma$ carboxy- $\gamma$-lactams. J Heterocyclic Chem 50:955-958.

Thaqi A, McCluskey A, Scott J L (2008) A mild Boc deprotection and the importance of a free carboxylate. Tetrahedron Lett 49:6962-6964. 
Verdié P, Subra G, Averland-Petit M-C, Amblard M, Martinez J (2008) Solid-phase synthesis of 4-methylcarbpxy1,4-benzodiazepine-2,5-diones. J Comb Chem 10:869-874.

Winn M et al (1997) Endothelin antagonists. US, 6162927.

Winitz M, Bloch-Frankenthal L, Izumiya N, Birnbaum S M, Baker C G, Greenstein J P (1956) Studies on diastereoisomeric alpha-hydroxy acids. Influence of beta-configuration on enzymic susceptibility. J Am Chem Soc 78:2423-2430.

Xu P, Lin W, Zou X (2002) Synthesis of a peptidomimetic HCMV protease inhibitor library. Synthesis 1017-1026. Zhao J, Kang G, Wang W, Zhao M, Zhang X, Lu C, Mao W, Chang H W, Ye W, Peng S (2009) N-[2-chloro-9Hpurin-6-yl]- $N$-cyclopropylglycylamino acids and derivatives: synthesis, evaluation as a class of novel analgesics, and 3D QSAR analysis. Bioorg Med Chem 17:6305-6310.

Zervas L, Winitz M, Greenstein J P (1957) Arginine peptides. I. Intermediates in the synthesis of N-terminal and C-terminal arginine peptides. J Org Chem 22:1515-1521. 